\title{
The role of ultrasound in assessing acute right iliac fossa pain
}

\begin{tabular}{l}
\hline Soran Sdeek Ahmed ${ }^{1}$ \\
\hline \multicolumn{1}{c}{ Abstract } \\
Background and objective: Abdominal ultrasound can provide an effective, \\
non-invasive, fast, inexpensive, and safe procedure with no risk of radiation to patients. \\
Accordingly, this study aimed to assess the role of ultrasonography in differentiating \\
causes of right iliac fossa pain among patients admitted to emergency hospitals in Erbil \\
City.
\end{tabular}

Methods: In this cross-sectional study, 120 patients with acute abdominal pain and tenderness of right lower quadrant (iliac fossa) region, clinically suspected to have acute appendicitis admitted to the emergency hospitals in Erbil city were included in the study, from April 2011 to February 2012. The data was collected through a direct interview of patients, followed by a sonographic examination.

Results: The prevalence of true positive sonographic examination was $60.8 \%$, with only $30 \%$ true negative findings. Around $69 \%$ of the cases had acute appendicitis, followed by ovarian cyst and right ureteric stone $(11.1 \%$ and $7.4 \%$, respectively). The sensitivity of sonographic examination in identifying appendicitis was $90.1 \%$, the specificity was $92.3 \%$. The positive predictive was $96 \%$, while the negative predictive value was $81.8 \%$. Sonographic characteristics of the positive patients with appendicitis showed that $58.0 \%$ of the patients had swollen appendix, and a diameter of $7.1-8 \mathrm{~mm}$ was the most imaging finding. Also, appendicitis was significantly $(P=0.02)$ more common $(58 \%)$ in males, and negative appendectomy was prevalent among females.

Conclusion: Appendicitis was the major cause of the right iliac fossa pain. Abdominal ultrasound was a reliable method in the diagnosis of the majority of patients with right iliac fossa pain and can decrease the rate of negative appendectomy.

Keywords: Ultrasound; Abdominal pain; Right iliac fossa; Acute appendicitis.

\section{Introduction}

The right iliac fossa is an anatomical term that refers to the right-inferior part of the surface of the human abdomen. ${ }^{1}$ It is a way of localizing pain and tenderness, scar, and lumps. The right iliac fossa is a common site of pain and tenderness in patients who have appendicitis. ${ }^{2}$ The fossa is named for the iliac fossa of the hip bone. Most of the anatomical structures that will produce pain and tenderness in this region are not, in fact, in the concavity of ileum. ${ }^{3}$ The most important contents of the right iliac fossa region are an appendix, caecum, part of ascending colon, and small intestine. The appendix can be localized, according to Mc. Burney point, a point which is located at lateral one-third of the line joining between the anterior superior iliac spine and umbilicus. However, the appendix shows various positions; it is a blind-ended tube that is 5 to $10 \mathrm{~mm}$ in diameter on ultrasound study and approximately $8 \mathrm{~cm}$ in length, although it may be up to $30 \mathrm{~cm}$ long. ${ }^{3,4}$ Right iliac fossa pain represents about $50 \%$ of all cases of acute abdomen pain. ${ }^{5}$ In surgery, the preoperative clinical diagnosis of acute appendicitis is correct in

1 Ministry of Health, Erbil, Iraq.

${ }^{2}$ Department of Surgery, College of Medicine, Hawler Medical University, Erbil, Iraq.

* Correspondence: drsalwarad25@yahoo.com 
only about $50 \%$ of cases. ${ }^{6}$ Appendicitis is more common in men; appendectomy is performed more in women, and women are more likely to have a normal appendectomy. ${ }^{7}$ About $10 \%$ of the population will develop acute appendicitis, and the incidence falls with age with peak age between 15 and 20 years. Pain in the right iliac fossa immediately raises the suspicion of appendicitis. ${ }^{8}$ But there are also many other causes to be considered when patients present with RIF pain, which may include; appendicitis, right ureteric stone, ovarian cyst/torsion, pelvic inflammatory diseases, mesenteric lymphadenitis, ectopic pregnancy, diverticulitis, intussusception, and malignancy. ${ }^{9}$ The sonography can be a definitive study for confirmation or exclusion of appendicitis. ${ }^{10}$ The reported sensitivity in examinations of adults was 57 - $98 \%$, and the specificity was $74-98 \%{ }^{11,12}$ The presence of an appendicolith which is seen in about $10 \%$ of the cases even in the normal-appearing appendix is generally regarded as a sign of appendicitis. ${ }^{13-15}$ However, many other conditions, as mentioned in the differential diagnosis, could mimic acute appendicitis. The most common conditions in the childbearing age women include pelvic inflammatory diseases, ruptured ectopic pregnancy, and ruptured ovarian cysts. Mesenteric lymphadenitis is also a common differential diagnosis in children. ${ }^{16-19}$ Ultrasonography is a non-invasive and cost-effective technique carrying no risk to the patient. However, positive ultrasound findings have a relatively high positive- predictive value, but sometimes identification of a normal appendix is sometimes difficult. ${ }^{20,21}$ Additionally, it was found that very little work has been done in our region/ country on the subject, and during our practice, we had noticed difficulties in diagnosing appendicitis cases on the clinical basis only. Accordingly, the current study aimed to assess the role of ultrasonography in differentiating causes of right iliac fossa pain among patients admitted to emergency hospitals in Erbil City.

\section{Methods}

In this cross-sectional study, a total of 120 patients with acute abdominal pain and tenderness of right lower quadrant (iliac fossa) region, clinically suspected to have acute appendicitis admitted to the emergency hospitals in Erbil city (Central Emergency, East Emergency and West Emergency Hospitals) were included in the study, from the period April 2011 to February 2012. Patients less than 12 years old were excluded from the study. For data collection, a questionnaire was designed by the researchers to describe the history and ultrasound findings of the studied patients. After obtaining approval from the administration of emergency hospitals, verbal consent was obtained from all the enrolled patients. They were informed of the purpose and the procedure of the study and were ensured that the obtained information will be kept confidential and would be used for the research purpose only. The data was collected through a direct patient interview, followed by a sonographic examination. All the enrolled patients underwent ultrasound examination preoperatively (irrespective of the menstruation days in females). Ultrasound Siemens, type G50 version 2011, Philips type HDXE version 2010, and Medison type SA8000 version 2009 were used for patients' abdominal sonography. The trans -abdominal examination was performed with patients lying in the supine position using the low-frequency curve probe of 3- $4 \mathrm{MHz}$ and high-frequency linear probe of $6-9 \mathrm{MHz}$. For the pelvic ultrasound, the patients were examined with urinary bladder adequately distended, to displace the small bowel from the field of view, and to provide acoustic window, and it was done by using a $3.5 \mathrm{MHz}$ probe to see any abnormality. The right iliac fossa region was examined with high $7.5 \mathrm{MHz}$ frequency probe to see the right common iliac artery, vein and psoas muscle for 
localization of appendix with scanning the area in transverse, longitudinal and oblique positions to see if its inflamed or if there are any other abnormalities rather than appendicitis. All the patients were operated on by open surgery and followed up for at least three days from their admission to the emergency hospitals, and all the sonographic positive patients followed postoperatively too, those with gross inflamed appendix regarded as true positive (confirmed by histo-pathological examination), while normal or normal looking appendix was proved by histopathological examination too. Ethical approval was obtained from the research ethics committee of the College of Medicine- Hawler Medical University. SPSS version 18 was used for data entry and analysis. Frequencies and percentages were used to generate tables and graphs, in addition to the Chi-square test to find out the association between different variables. Fisher's exact test was used when the expected count of more than $20 \%$ of the cells of the table was less than 5. A $P$ value $\leq 0.05$ was considered as statistically significant.

\section{Results}

There were $50(41.6 \%)$ males and 70 $(58.4 \%)$ females patients with a mean age of 23.3 years, ranging from 13 to 50 years, with a male to female ratio of $0.7: 1$. The prevalence of true positive sonographic examination was $60.8 \%$, with only $30 \%$ true negative findings. The sensitivity of sonographic examination in identifying appendicitis was $90.1 \%$, the specificity was $92.3 \%$. However, the positive predictive value of sonography was $96 \%$, while the negative predictive value was $81.8 \%$ (Table 1).

Table 1: Diagnostic indices of the patients by sonography $(n=120)$.

\begin{tabular}{ll}
\hline Diagnostic indices & Values (\%) \\
\hline True positive (TP) & $73(60.8 \%)$ \\
True negative (TN) & $36(30.0)$ \\
False positive (FP) & $3(2.5 \%)$ \\
False negative (FN) & $8(6.6 \%)$ \\
Sensitivity & $90.1 \%$ \\
Specificity & $92.3 \%$ \\
Positive predictive value (PPV) & $96.0 \%$ \\
\hline
\end{tabular}


The role of ultrasound in assessing acute right .......

https:// doi.org/10.15218/zjms.2020.007

Ultrasound findings of positive sonography patients revealed that more than twothirds $(69.0 \%)$ of the cases had acute appendicitis, followed by right ureteric stone and ovarian cyst $(3.7 \%$ and $11.1 \%$, respectively), (Table 2, Figure 1). Sonographic characteristics of the positive patients with appendicitis showed that more than half $(58.7 \%)$ of the patients had swollen appendix, followed by free fluid collection and appendicolith $(15.9 \%$ and $15.9 \%$, respectively), (Table 3 ). It is worth to mention that the eight negative cases by sonography had not revealed any of the characteristics mentioned below.

Table 2: Ultrasound findings of sonographic positive patients $(n=81)$.

\begin{tabular}{lcc}
\hline Ultrasound findings & No. of the patients & Percentage (\%) \\
\hline Appendicitis & 56 & $(69.1)$ \\
Ovarian cyst & 9 & $(11.1)$ \\
Right ureteric stone & 6 & $(7.4)$ \\
Mesenteric lymphadenitis & 5 & $(6.2)$ \\
Rupture ectopic pregnancy & 3 & $(3.7)$ \\
Dermoid cyst & 2 & $(2.5)$ \\
\hline
\end{tabular}

Table 3: Sonographic characteristics of positive patients with appendicitis.

\begin{tabular}{lcc}
\hline Sonographic findings & No. of patients & Percentage (\%) \\
\hline Swollen appendix & 47 & $(58.0)$ \\
Free fluid & 15 & $(18.5)$ \\
Appendicolith & 13 & $(16.0)$ \\
Echogenic peri-appendiceal fat & 6 & $(7.4)$ \\
Total & $\mathbf{8 1}$ & $\mathbf{( 1 0 0 )}$ \\
\hline
\end{tabular}

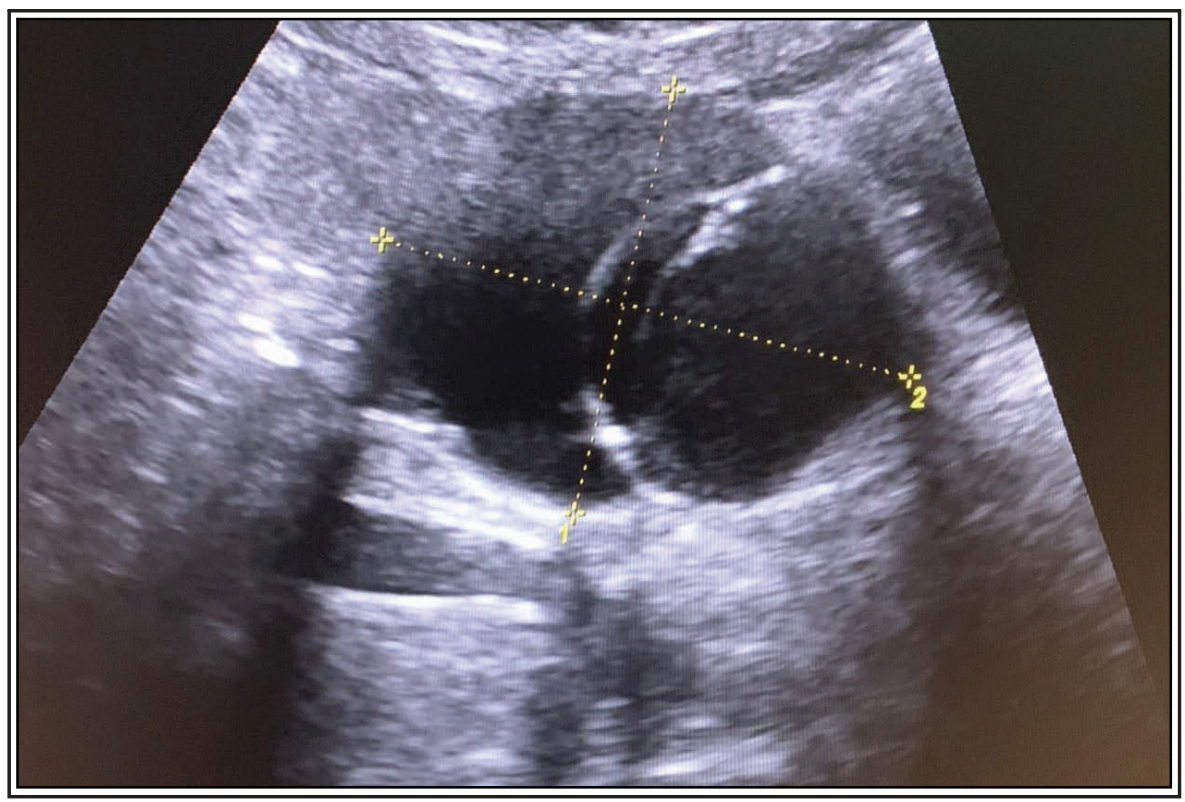

Figure 1: Ultrasound image of complicated right ovarian cyst. 
The role of ultrasound in assessing acute right .......

https://doi.org/10.15218/zjms.2020.007

Swollen appendix with a diameter of 7.1- 8 $\mathrm{mm}$ was the most imaging finding (59.6\%) among the appendicitis cases with appendicular mass, followed by $8.1-10 \mathrm{~mm}$ and $\leq 7 \mathrm{~mm}$ diameter $(21.3 \%$ and $14.9 \%$, respectively), (Table 4, Figure 2). The study also revealed that appendicitis was more common in males (58\%) than females (42\%). However, negative appendectomy was more common in females compared to males $(7.1 \%$ and $0.0 \%$, respectively) with no significant statistical difference $(P=0.074)$, (Table 5).

Table 4: Diameter of the appendix $(\mathrm{mm})$ in cases of appendicular mass by sonography.

\begin{tabular}{lcc}
\hline Diameter of the appendix $(\mathbf{m m})$ & No. of patients & Percentage $(\%)$ \\
\hline$\leq 7$ & 7 & $(14.9)$ \\
$7.1-8$ & 28 & $(59.6)$ \\
$8.1-10$ & 10 & $(21.3)$ \\
$10.1-15$ & 2 & $(4.3)$ \\
${ }^{*}$ Total & $\mathbf{4 7}$ & $(\mathbf{1 0 0})$ \\
\hline
\end{tabular}

Table 5: Relationship between negative appendectomy and gender of the patients.

\begin{tabular}{lccc}
\hline Negative appendectomy & $\begin{array}{c}\text { Male } \\
\text { (No. \& \%) }\end{array}$ & $\begin{array}{c}\text { Female } \\
\text { (No. \& \%) }\end{array}$ & P value \\
\hline Yes & $0(0.0)$ & $5(7.1)$ & $0.074^{*}$ \\
No & $50(100.0)$ & $65(92.9)$ & \\
Total & $50(100)$ & $70(100)$ & \\
\hline
\end{tabular}

${ }^{*}$ Fischer's exact test

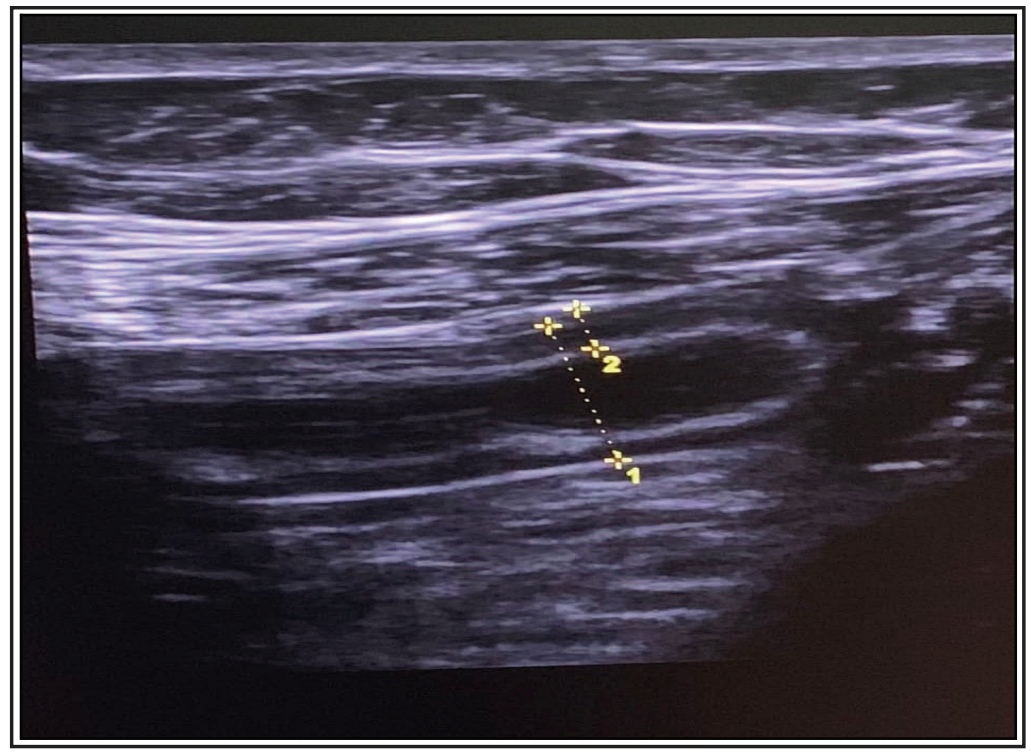

Figure 2: Ultrasound of appendix with thick wall more than $6 \mathrm{~mm}$. 


\section{Discussion}

To improve the diagnostic accuracy of cases presented with right iliac fossa pain, especially acute appendicitis, crosssectional imaging modalities such as ultrasonography is widely used, this imaging modality, in addition to the clinical evaluation, is of considerable value in patients with atypical presentation or equivocal clinical findings. ${ }^{22}$ The study showed that the mean age of the patients was 23.3 years, ranging from 13 to 50 years. However, a study in the USA revealed that acute appendicitis was most common in patients 10- 19 years old. The mean age at diagnosis has increased over time for the period of 1993 to 2008. ${ }^{23}$ This may reflect the variation of data over several countries and regions, which might be due to different cultural, lifestyle behaviors, and environmental factors. This study had shown that the prevalence of real confirmed appendicitis by sonographic examination was $60.8 \%$, with only one-third had true negative findings. Among all true positive cases, around two-thirds were acute appendicitis indicating that inflamed appendix was the commonest cause of right iliac fossa pain. Similar results were reported in a Pakistani study. ${ }^{24}$ However, a study in Brazil showed low sensitivity and specificity and little contribution of sonography in the diagnosis of acute appendicitis. $^{25}$ Type of the sonographic machines and experience of radiologists could play an important role in the early diagnosis of appendicitis. In this study, the sensitivity of sonographic examination in identifying appendicitis was $90.1 \%$, and the specificity was $92.3 \%$. However, the positive predictive value was $96 \%$, while the negative predictive value was $81.8 \%$, with a total agreement of $90.8 \%$. Almost similar results were reported in studies in France, the USA, Nepal, and Japan., 41,26,27 This indicates that ultrasound can diagnose a wide variety of conditions, so it enhances the diagnosis accuracy in cases with right iliac fossa pain and consequently reduces the number of negative appendectomies and perforation rate. Ultrasound findings of positive sonography patients revealed that more than two- thirds of the cases had acute appendicitis, followed by the ovarian cyst and right ureteric stone. Studies in Iraq (In both Basrah and Erbil) revealed that appendicitis was positive in the majority of the patients. ${ }^{28,29}$ Another study in Nepal showed that $17.5 \%$ of the cases had alternate diagnosis apart from appendicitis. ${ }^{26}$ Skills and experience of the radiologist might contribute to the proper filtration of cases with right iliac fossa pain, with the provision of proper diagnosis, especially in females. Sonographic characteristics of the positive patients with appendicitis showed that more than half of the patients had swollen appendix, followed by free fluid collection and appendicolith. A study in Greece had shown that most of the patients had a free fluid collection in the pouch of Douglass, and around $15 \%$ of men and $3.3 \%$ of women displayed the presence of appendicolith. ${ }^{30}$ These findings confirmed the value of ultrasonography in the diagnosis of the cases with right iliac fossa pain, especially appendicitis, and has produced comparable results to these studies mentioned above. In this study, a swollen appendix with a diameter of 7.1- $8 \mathrm{~mm}$ was the most common imaging finding in nearly two-thirds of appendicitis cases. Studies in Nepal and Austria revealed that the diagnosis should be considered with the diameter of appendix over $6 \mathrm{~mm} .{ }^{26,31}$ However, a study in Belgium indicated that the outer diameter of the appendix of $6 \mathrm{~mm}$ or more could not be considered as a dependable criterion for the diagnosis of appendicitis in patients having cystic fibrosis. ${ }^{32}$ The variations across different studies could be attributed to the associated co-morbidities and time of onset of the sonographic examination. Also, the study revealed that appendicitis was significantly more common in males. A study in Iran revealed that appendicitis was more common in males. ${ }^{33}$ While a study in Brazil showed no gender effect 
of sonography. ${ }^{25}$ The gender variation of acute appendicitis could give the impression that epidemiologic features of acute appendicitis are different from worldwide data. However, negative appendectomy was more common in females compared to males. Similar results were revealed in studies in Iraq, the USA, and Pakistan. ${ }^{29,34,35}$ Gynecologic conditions, including the ovaries and ovarian cysts, are the most common misdiagnosed conditions as an appendiceal disease in women. Also, the experience of the radiologist and time of the onset of the symptoms could affect the differential diagnosis of appendicitis, especially in females.

\section{Conclusion}

This study had concluded that abdominal ultrasound was a reliable method in the diagnosis of the majority of patients with right iliac fossa pain and can decrease the rate of negative appendectomy as the appendicitis was the major cause of the right iliac fossa pain, and was more dominant among males. Accordingly, every case of right iliac fossa pain should be carefully evaluated by detailed, meticulous ultrasound for the diagnosis of the main problem, which could be any cause other than acute appendicitis, especially in childbearing age women.

\section{Competing interests}

The authors declare no competing interests.

\section{References}

1. Wilson SR. Gastrointestinal sonography. Abdom Imaging 2002; 21:1-11.

2. Puylaert JB. Ultrasound of acute $\mathrm{Gl}$ tract conditions. Eur Radiol 2001; 1:1867-77.

3. Sabatino A, Armellini E, Corazza GR. Doppler sonography in the diagnosis of bowel disease. Dig Dis 2004; 22:63-6.

4. Schmutz GR, Benko A, Fournier L, Peron JM, Morel E, Chiche L.. Small bowel obstruction: role and contribution of sonography. Eur Radiol 2007; 7:1054-8.

5. Lim JH, Ko YT, Lee DH, Lee HW, Lim JW. Determining the site and causes of colonic obstruction with sonography. AJR Am J
Roentgenol 2001; 163:1113-7.

6. Attard AR, Corlett M J, Kinder N J, Leslie AP, Fraser IA. Safety of early pain relief for acute abdominal pain. Br Med J 2002; 305:554-60.

7. Engstrom L, Fenyo G. Appendicectomy: assessment of stump invagination, a prospective randomised trial. Br J Surg 2003; 72:971-2.

8. F Stuart, Morrisson I. The acute abdomen. Sutton $\mathrm{D}$ (editor). Textbook of radiology and imagining. $9^{\text {th }}$ ed. London: Churchill Livingstone; 2003. P. 683-5.

9. Jeffrey RB, Jain KA, Nghiem HV. Sonographic diagnosis of acute appendicitis: interpretive pitfalls. Am J Roentgenol 2005; 162:55-9.

10. Kessler N, Cyteval C, Gallix B, Lesnik A, Blayac PM, Pujol J, et al. Appendicitis: Evaluation of sensitivity, specificity, and predictive values of US, Doppler US, and laboratory findings. Radiology 2004; 230:472-8.

11. Pickhardt PJ, Levy AD, Rohrmann CA JR, Kende Al. Primary neoplasms of the appendix: radiologic spectrum of disease with pathologic correlation. Radiographics 2003; 23:645-62.

12. van Breda Vriesman AC, Puylaert JB. Epiploic appendagitis and omental infarction: pitfalls and look-alikes. Abdom Imaging 2002; 27:20-8.

13. Jones P F. Suspected acute appendicitis: trends in management over the past 30 years. $\mathrm{Br} \mathrm{J}$ Surg 2001; 88:1570-7.

14. Nitecki S, Assalia A, Schein M. Contemporary management of the appendiceal mass. Br J Surg 2009; 80:18-20.

15. Shelton T, McKinlay R, Schwartz RW. Acute appendicitis: current diagnosis and treatment. Curr Surg 2003; 60:502-5.

16. Assefa G, Meseret S, Nigussie $Y$. The role of ultrasound in diagnosing acute appendicitis. Ethiop Med J 2006; 44:67-74.

17. Benjamin IS, Patel A G. Managing acute appendicitis. Br Med J 2002; 325:505-6.

18. Beasley SW. Can we improve diagnosis of acute appendicitis? Br Med J 2000; 321:907-8.

19. Abu-Yousef MM. Ultrasonography of the right lower quadrant. Ultrasound Q 2001; 17:211-5.

20. Puylaert JB, Van der Zant FM, Rijke M: Sonography and the acute abdomen: practical considerations. AJR Am J Roentgenol 2006; 168:179-86.

21. Friday $\mathrm{JH}$. Update on appendicitis: Diagnosis and pre-surgical management. Curr Opin Pediatr 2006; 18:234-8.

22. Rettenbacher $\mathrm{T}$, Hollerweger A, Gritzman N, Gotwald T, Shwanmberger K, Ulmer H, et al. Appendicitis: Should diagnostic imaging be performed if the clinical presentation is highly suggestive of the disease? Gastroenterol 2002; 123:992-8.

23. Buckius MT, McGrath B, Monk J, Grim R, Bell T, Ahuja V. Changing Epidemiology of Acute Appendicitis in the United States: Study Period 1993-2008. J Surg Res 2012; 175:185-90. 
24. Sherazi AS, Sametzadeh M, Kamankesh R, Rahimi F. Accuracy of sonography in the diagnosis of acute appendicitis. Pak J Biol Sci 2010; 13:190-3.

25. Peixoto RO, Nunes TA, Gomes CA. Indices of diagnostic abdominal ultrasonography in acute appendicitis. Influence of gender and physical constitution, the time evolution of the disease and experience of the radiologist. Rev Col Bras Cir 2011; 38(2):105-11.

26. Khanal BR, Ansari MA, Pradhan S. Accuracy of ultrasonography in the diagnosis of acute appendicitis. Kathmandu Univ Med J 2008; 6:704.

27. Himeno S, Yasuda S, Oida Y, Mukoyama $\mathrm{S}$, Nishi T, Mukai M, et al. Ultrasonography for the diagnosis of acute appendicitis. Tokai J Exp Clin Med 2003; 28:39-44.

28. Helo HR. The effectiveness of ultrasound imaging in the diagnosis of acute appendicitis. Basrah J Surg 2012; 18:89-96.

29. Amedy MM. The accuracy of ultrasound in the diagnosis of right iliac fossa pain in Erbil city. M.Sc. Thesis in radiology. College of Medicine; 2005.

30. Xifara S, Katergianakis V, Vlastarakos $P$, Skaltsas S, Loulakas I, Bramis I. The role of ultrasound in the diagnosis of acute appendicitis. Hellenic J Surg 2013; 85(1):35-41.

31. Rettenbacher T, Hollerweger A, Macheiner P, Rettenbacher L, Tomaselli F, Schneider B, et al. Outer diameter of the vermiform appendix as a sign of acute appendicitis: evaluation at US. Radiology 2001; 218(3):757-62.

32. Menten R, Lebecque P, Saint-Martin C, Clapuyt $P$. Outer diameter of the vermiform appendix: not a valid sonographic criterion for acute appendicitis in patients with cystic fibrosis.AJR Am J Roentgenol 2005; 184(6):1901-3.

33. Noudeh $Y J$, Sadigh $N$, Ahmadnia AY. Epidemiologic features, seasonal variations and false positive rate of acute appendicitis in Shahre-Rey, Tehran. Int J Surg 2007; 5:95-8.

34. Seetahal SA, Bolorunduro OB, Sookdeo TC, Oyetunji TA, Greene WR, Frederick W, et al. Negative appendectomy: a 10-year review of a nationally representative sample. Am J Surg 2011; 201(4):433-7.

35. Memon ZA, Irfan S, Fatima K, Iqbal MS, Sami W. Acute appendicitis: diagnostic accuracy of Alvarado scoring system. Sian J Surg 2013; 36(4):144-9. 